\title{
Cobweb Model with Buffer Stock for the Stabilization of Tomato Prices in Ghana
}

\author{
Martin Anokye ${ }^{1} \&$ Francis T. Oduro ${ }^{2}$ \\ ${ }^{1}$ Kumasi Polytechnic, Ghana \\ ${ }^{2}$ Kwame Nkrumah University of Science and Technology, Ghana \\ Correspondence: Francis. T. Oduro, Kwame Nkrumah University of Science and Technology, Ghana. E-mail: \\ ftoduro@math-knust.edu.gh
}

Received: March 22, $2012 \quad$ Accepted: December 25, $2012 \quad$ Online Published: January 16, 2013
doi:10.5539/jms.v3n1p155
URL: http://dx.doi.org/10.5539/jms.v3n1p155

\begin{abstract}
In this paper a linear cobweb model is developed to study the phenomenon of commodity price fluctuations and then a buffer stock incorporated into the model to stabilize the price of fresh tomatoes in Ghana. The model performed on the assumptions that fresh tomatoes have no equal substitutes, and that there is no foreign competition and also no exogenous shocks needed to generate price fluctuations.
\end{abstract}

The analysis detected that the slope of the demand function of price was smaller than the slope of the supply function of price curve implying that the price and quantity supplied of the fresh tomatoes would oscillate around a fixed price and quantity and also spiral outward.

The "Keep Supply at Average" (KSA) buffer scheme achieved price and quantity stability in the short run. The mean price of the scheme was GH $\notin 17.31$, very close to actual price mean of Gh $\varnothing 13.40$ in the first 16 quarters. The standard deviation of the scheme price also dropped to 1.2 from 9.13 during price stabilization compared to 14.60 of actual price mean.

In the long run the scheme price went up to Ghф 18.22, an increase of Ghф 0.91 and it is clear that in long run buffer system will fail unless the average supply is reviewed regularly.

The scheme price trend equation indicated that with the implementation of the buffer scheme, the average quarterly price of fresh tomatoes increased by only 0.05 .

Keywords: cobweb model, buffer stock, commodity price stabilization

\section{Introduction}

Tomato production in Ghana is mainly a smallholder activity, and its distribution throughout the year is markedly seasonal, agriculture here being largely rain fed.

Lack of a secured ready market for fresh tomatoes during periods of bumper harvest coupled with the absence of post harvest management of the crop has been a major concern to most farmers who often run into debt as a result.

Thus, unlike grains, the bulky and perishable nature of tomatoes, coupled with the lack of processing and storage facilities in Ghana, constitute critical impediments to the commodity's inter-market arbitrage by traders (Amikuzuno, 2009; Kokutse, 2010).

The goal of this study is to investigate the phenomenon of commodity price fluctuations using the cobweb model incorporating buffer stock for stabilizing price of fresh tomatoes under limited time of supply and continuous consumption.

With the application of Box-Jenkins method to Ghana data, the supply and demand functions price of fresh tomatoes using time series analysis would also be characterized.

Detecting sources of price fluctuations is one of the most important subjects in agricultural economics. In the thirties, the observation of regularly recurring cycles in the production and prices of particular commodities gave birth to the cobweb model (Ezekiel, 1938). This model describes price fluctuations in a single market for a commodity that takes one unit of time to produce.

Supply depends on the expectations of the producers about next period's price and market prices are driven by 
these expectations. When both the demand and the supply curves are linear, then only three types of price dynamics can occur:

(i) Convergence to a stable equilibrium (convergent fluctuation),

(ii) Convergence to a period-2 cycle, the so-called 'hog-cycle' (continuous fluctuation) or

(iii) Exploding oscillations (divergent fluctuation).

The cobweb model has been studied in many ways since Ezekiel (1938) developed it to explain the corn-hogs cycle that had been observed in the United States, The cobweb model has difficulty in explaining the irregular fluctuations observed in the actual data. Thus, explaining variations in production requires including uncertain or stochastic factors like good or bad weather or complicated factors like multi-period production lags.

The recent literature, which takes account of developments in nonlinear economic dynamics, demonstrates that the cobweb model can generate irregular fluctuations of price or output if the demand curve and/or the supply curve have strong nonlinearities (Hommes, 1994). These findings indicate that irregular fluctuations may arise from the intrinsic working of pure economic factors (i.e., demand and supply) in the deterministic cobweb model (Matsumoto,1998). Fluctuations are therefore proposed to arise based on the following two main explanations.

\subsection{The Exogenous Factors Explanation}

The exogenous factors (Cafiero \& Wright, 2006; Deaton \& Laroque, 2003; 1992) such as weather shocks or any other factors outside the economic environment could perturb supply. For example, climatic fluctuations may be responsible of price fluctuations.

Food and Agriculture Organization (2006) reports that Ghana`s reduction in agricultural import tariffs in the year 2000 stimulated an influx of cheap but high quality agricultural commodities into Ghana.

For fresh tomatoes, increased importation of tomato products is believed to be the cause of a sustained erosion of real producer prices, rapid and post-liberalisation price volatility and supply gluts.

The reason attributed to this is that imported tomato paste/ketchup is an excellent substitute for locally produced fresh tomato because of their low price, high shelf life and quality.

\subsection{The Endogenous Factors Explanation}

The endogenous factors explanation is tricky, but more plausible. Expectations of producers about future prices are assumed to be based on observations of previous prices.

According to Ezekiel (1938), erroneous expectations lead to over- or under- supply since, in both cases, an inelastic demand magnifies imbalances and creates large and detrimental price fluctuations. (Nerlove, 1958) further made the assertion that agents only use recent past data to form their price expectations and make systematic forecast errors, which lead to over or under supply. These errors are what lead to endogenous fluctuations in the cobweb model.

Nerlove (1958) states that while assuming that farmers look back at the most recent prices in order to forecast future prices might seem very reasonable, this backward-looking forecasting (which is called adaptive expectations) turns out to be crucial for the model's fluctuations.

When farmers expect high prices to continue, they produce too much and therefore end up with low prices, and vice versa.

According to (Evans \& Honkapohja, 2001) in regards to adaptive expectations, people form their expectations about what will happen in the future based on what has happened in the past.

Rational expectations is another endogenous factor in economics which states that agents' predictions of the future value of economically relevant variables are not systematically wrong in that all errors are random (Muth ,1961; Sargent \& Savin, 1987). Rational expectations are model-consistent expectations, in that the agents inside the model assume the model's predictions are valid.

This expectation assumes that agents' expectations may be individually wrong, but are correct on average because forecast do not differ systematically from the market equilibrium results and deviations from perfect foresight are only random. In an economic model, this is typically modelled by assuming that the expected value of a variable is equal to the expected value predicted by the model (Muth, 1961; Sargent \& Savin, 1987).

In a model like that of Deaton and Laroque $(1992,1996)$ with production engendered by a zero mean stationary process, it is possible to assume that decision makers know the probability distribution of shocks, (and therefore, of prices), conditional to the current volume of the stock (if known at decision time, which is at least discussible). 
This is a way of representing rational expectation based on abundant yet incomplete information (next year's actual price is not known with certainty). Here, agents have less information, since the probability distribution of prices is not known.

The naïve or static expectation on the other hand assumes that the best forecast of future price is current price. This expectation mechanism ignores possible producer knowledge of anticipated supply or demand shifts and their effects on price (Gomez, Love \& Burton, 1999).

\subsection{Stabilization of Price}

Stabilizing fluctuations is another important subject in agricultural economics. In order to regulate prices, to guarantee producers' incomes, and to iron out variations in production, the governments in many economies constantly intervene in agricultural markets in various ways. The intervention takes forms of the minimum and/or maximum price, tariff and quotas, subsidies, and production restriction. In consequence, government stabilization policy greatly affects prices and quantities of agricultural goods produced (Matsumoto, 1998 ).

\subsection{Price Stabilization Using Buffer Stock}

It is a well-known fact of economic reality that commodity prices are extremely volatile (Deaton \& Laroque, 1992). One of the instruments for price stabilization, which is found frequently in the economic literature, is the so-called buffer stock scheme.

The buffer stock scheme (commonly implemented as intervention storage) is an attempt to use commodity storage for the purposes of stabilizing prices in an entire economy or more commonly, an individual (commodity) market. Specifically, commodities are bought when there is a surplus in the economy, stored, and are then sold from these stores when there are economic shortages in the economy (Morrow, 1980; Edwards \& Hallwood, 1980).

It is assumed that government conducts buffer stock planning program, procurement planning program, inventory management program, market operation planning policy (Bahagia, 2006) and also controls the market and not in competition with any other storage firms.

It is shown that if the storage capacity for the commodity is sufficiently large then there exist a simple stabilization policy, called the 'keep supply at equilibrium (KSE)' policy, such that the equilibrium price is a global attractor for the corresponding closed-loop system.

In addition, it is shown that if the government approximates the equilibrium supply with the average supply, stabilization is guaranteed. We refer to this policy as "keep supply at average (KSA)" ( Athanasiou et al., 2010).

\section{Method}

This section introduces the data sources, discusses the demand and supply functions of price and production respectively and the difference equation that constitutes the cobweb model and then incorporates it with buffer stock for stabilization of price.

\subsection{Data Sources}

This paper uses quarterly recorded secondary data (table 1 and 2) of fresh tomatoes for the analysis. The price the data were obtained from the Ministry of Food and Agriculture Kumasi- Ghana covering the period between 1994 and 2009 while the production data were also obtained from the Ministry of Food and Agriculture Statistical Directorate Accra- Ghana covering the same period.

Table 1. Average production of fresh tomatoes in metric tons: modified

\begin{tabular}{lllll}
\hline Year & Quarter 1 & Quarter 2 & Quarter 3 & Quarter 4 \\
\hline 1994 & 709.75 & $1,170.28$ & 773.09 & 787.54 \\
1995 & $1,167.71$ & $1,242.78$ & 643.46 & 712.72 \\
1996 & $7,844.34$ & $9,628.37$ & $8,814.06$ & $4,880.89$ \\
1997 & $4,983.67$ & $5,373.71$ & $3,788.01$ & $1,195.94$ \\
1998 & $1,075.54$ & $4,774.62$ & $1,509.50$ & $1,203.01$ \\
1999 & $1,810.26$ & $2,956.33$ & $1,383.73$ & $1,554.35$ \\
2000 & $1,485.87$ & $2,842.31$ & $1,616.87$ & $1,896.95$ \\
2001 & $1,982.63$ & $2,844.06$ & $1,762.15$ & $1,645.16$ \\
2002 & $2,466.77$ & $3,394.95$ & $1,531.52$ & $1,333.43$ \\
2003 & $1,731.18$ & $3,605.52$ & $1,632.66$ & $2,527.31$ \\
\hline
\end{tabular}




\begin{tabular}{lllll}
\hline 2004 & $2,700.97$ & $2,862.68$ & $2,325.64$ & $2,109.71$ \\
2005 & $1,945.62$ & $4,950.15$ & $1,489.26$ & $1,814.97$ \\
2006 & $2,736.90$ & $3,608.29$ & $2,268.27$ & $2,029.55$ \\
2007 & $2,908.22$ & $5,276.02$ & $3,008.52$ & $3,280.58$ \\
2008 & $2,869.12$ & $4,101.02$ & $3,615.69$ & $3,727.17$ \\
2009 & $4,955.38$ & $6,599.39$ & $4,951.96$ & $3,309.94$ \\
\hline
\end{tabular}

Source: Ministry of Food and Agriculture, Statistical Directorate, Accra

Table 2. Average prices of tomatoes (rate of $52 \mathrm{~kg}$ ) in $\mathrm{GH} \phi$

\begin{tabular}{lllll}
\hline Year & Quarter 1 & Quarter 2 & Quarter 3 & Quarter 4 \\
\hline 1994 & 0.81 & 1.33 & 0.88 & 0.90 \\
1995 & 2.07 & 2.21 & 1.14 & 1.27 \\
1996 & 2.49 & 3.05 & 2.79 & 1.55 \\
1997 & 4.11 & 4.43 & 3.12 & 0.99 \\
1998 & 2.37 & 10.53 & 3.33 & 2.65 \\
1999 & 3.79 & 6.18 & 2.89 & 3.25 \\
2000 & 4.25 & 8.13 & 4.63 & 5.43 \\
2001 & 7.52 & 10.79 & 6.69 & 6.24 \\
2002 & 12.31 & 16.94 & 7.64 & 6.66 \\
2003 & 10.82 & 22.54 & 10.21 & 15.80 \\
2004 & 17.60 & 18.66 & 15.16 & 13.75 \\
2005 & 18.18 & 46.25 & 13.91 & 16.96 \\
2006 & 21.54 & 28.40 & 17.85 & 22.68 \\
2007 & 20.09 & 36.45 & 20.79 & 32.77 \\
2008 & 25.22 & 36.05 & 31.79 & 38.78 \\
2009 & 58.05 & 77.31 & 58.01 & \\
\hline
\end{tabular}

Source: Ministry of Food and Agriculture, Kumasi

\subsection{The Cobweb Model}

The supply and demand functions of prices of fresh tomatoes were obtained based on the following assumptions relative to consecutive time periods:

a. The supply in period $\mathrm{k}$ (where $\mathrm{k}=1,2,3, \ldots$ ) is a linear function of the price in previous period $\mathrm{k}-1$, with the supply increasing when prices increases.

b. The demand in period $\mathrm{k}$ is a linear function of the price in period $\mathrm{k}$, with the demand decreasing when price increases.

c. The market price is determined by the available supply, with the transaction taking place at the price which makes the demand equal to the supply.

For $\mathrm{k}=0,1,2,3, \ldots$ let

$\mathrm{S}_{\mathrm{k}}=$ nnumber of units of the commodity supplied in the kth period

$D_{k}=\{$ number of units of the commodity demand in the kth period $\}$

$\mathrm{P}_{\mathrm{k}}=$ \{price of a unit of the commodity in the kth period

(Fulford et al, 1997)

Given the price-demand and price-supply curves;

$$
\begin{gathered}
D_{k}=\alpha-\beta P_{k} \\
S_{k}=\delta+\gamma P_{k-1}
\end{gathered}
$$

where $-\beta$ and $\alpha$ represent the slope and intercept, respectively, for the demand curve, and $\Upsilon$ and $\delta$ represent the corresponding slope and constants for the supply curve (Ezekiel, 1938; Goldberg, 1986).

The assumption (c) translates to $\mathrm{Dk}=\mathrm{Sk}$ and hence obtain the first-order non-homogeneous difference equation from (1) and (2) as

$$
P_{k}=A P_{k-1}+B
$$


where $A=-\gamma / \beta$ and $B=(\alpha-\gamma) / \beta$ for $(\mathrm{k}=1,2,3, \ldots)$

The solution of first order equation (3) is given as

where $\mathrm{A} \neq 1$, and $\mathrm{k}=0,1,2, \ldots$

$$
P_{k}=A^{k} P_{0}+B\left(1-A^{k} / 1-A\right)
$$

The homogenous part of the solution is also given by: $P h_{k}=A^{k} P_{0}$

By using the lag operator on the relation (3) then

$$
P_{k}=\frac{B}{1-A L}
$$

As a constant is not changed by the application of the lag operator, the number ' 1 ' can substitute the lag operator in the corresponding term. Thus there can be no delay if we apply the lag operator on a constant (Kirchgässner \&Wolters, 2007) .

Hence

$$
P_{k}=B /(1-A)=(\alpha-\delta) /(\beta+\gamma)
$$

where $A=-\gamma / \beta$ and $B=(\alpha-\gamma) / \beta$

Let $\mathrm{P}_{\mathrm{e}}$ denotes the intersection of the deterministic parts of the demand and supply curves or the equilibrium price (point) then;

where $P_{e} \geq 0$ if $\alpha \geq \delta$

$$
P_{e}=P_{k}=(\alpha-\delta) /(\beta+\gamma)
$$

In this case the system is in equilibrium when the price remains constant for all time periods, i.e

$$
P_{k}=P_{k-1}=\ldots=P_{e}
$$

\subsection{Convergence Conditions}

If $\Upsilon \prec \beta$ or $\beta \succ \Upsilon$, then the price and quantity will go up and down around the equilibrium price and quantity, and the fluctuating scope will become smaller and smaller, and finally converge to the equilibrium point.

However, if $\beta \prec \Upsilon$ or $\Upsilon \succ \beta$ then the price and quantity will go up and down around the equilibrium price and quantity, and the fluctuating scope will become bigger and bigger, and will never converge to the equilibrium point.

Also if $\Upsilon=\beta$, then price and quantity will go up and down around the equilibrium price and quantity, and the fluctuating scope will remain the same and will never converge to the equilibrium point (Ruize, 2010).

\subsection{Model with Buffer Stocks: Naïve Expectation}

To make the analysis tractable we assume that the interest rate is zero and that there are no inventory losses. In order to introduce stockpiling into our model we define two variables:

$\mathrm{Q}_{\mathrm{k}-1}$ is a state variable which denotes the government inventory at period k-1 and

$G_{k-1}$ a control variable which denotes the quantity of the commodity released to the market by the government at period $\mathrm{k}$.

When $G_{k-1}<0$ then the government buys and stores $\left|G_{k-1}\right|$ commodity units at period k.

Furthermore, the inventory must satisfy the following difference equation for all periods

$$
Q_{k}=Q_{k-1}-G_{k-1}
$$

At the market clearing condition

$$
D_{k}=S_{k}-G_{k-1}
$$

Therefore

$$
\alpha-\beta P_{k}=\delta+\gamma P_{k-1}+G_{k-1} \text { with } P_{k}=A P_{k-1}+B \text { where } A=-\gamma / \beta \text { and } B=\left(\alpha-\gamma-G_{k-1}\right) / \beta
$$


The solution is then given as

$$
P_{k}=A^{k} P_{0}+B\left(\frac{1-A^{k}}{1-A}\right) \text { Where } \mathrm{A} \neq 1, \text { for } \mathrm{k}=0,1,2, \ldots,
$$

In the absence of government intervention $G_{k-1}=0$ the corresponding dynamical system (7) reduces to the standard cobweb model with a piecewise linear supply function (the state variable $Q_{k}$ does not affect the system).

\subsection{Keep Supply at Average (KSA)}

If government fixes supply of fresh tomatoes at the average supply $S_{k}^{A}=\sum_{j=1}^{k} s_{t-j} / k$, stabilization is guaranteed and we refer to this policy as keep supply at average (KSA). In this case the average price is a global attractor for the corresponding closed-loop system and in order to solve the problem we set

$$
G_{k-1}=\min \left\{Q_{k-1} ; \max \left\{S_{k}^{A}-g\left(P_{k-1}^{e}\right) ; Q_{k-1}-Q_{m}\right\}\right\}
$$

where $g\left(P_{k-1}^{e}\right)$, is the estimated supply at period $\mathrm{k}$ and $\mathrm{Q}_{\mathrm{m}}$ is the storage capacity.

This equation attempts to bring the total quantity of the commodity available in the market at period $\mathrm{k}$ given by $\mathrm{S}_{\mathrm{k}}+\mathrm{Gk}_{-1}$ which is close as possible to the equilibrium supply $S_{k}^{A}$.

According to this policy rule, when the difference between the average supply and available supply is positive then the market runs short of the commodity and the government intervenes by selling a certain quantity of the commodity. Of course the quantity released at period k cannot exceed the quantity stored at period k- 1 . When the difference between the average (equilibrium) supply and the available supply is negative, then there is abundance of the commodity and the government buys a certain quantity of the commodity (Athanasiou et al., 2008).

\section{Results and Discussion}

The general objective of this study is to investigate the phenomenon of commodity price fluctuations in the context of the cobweb model of mathematical economics.

SPSS was used to model and estimate the model parameters of the first order difference equations of the demand and supply functions of price. The two equations were combined into a single first-order difference equation constituting the cobweb model. An additional component was later introduced into the model as buffer stock.

Minitab and SPSS as software packages were used for the analysis of data and modeling.

\subsection{Demand Function of Price}

The production and price data series were prepared for analysis to derive demand function of price with both data sets at the same level after they have been stationarized at order one and two differencing for price and production data respectively. The two data sets were regressed and we obtained the following results;

\begin{tabular}{|c|c|c|c|c|c|}
\hline Model & \multicolumn{2}{|c|}{ Unstandardized Coefficients } & \multicolumn{3}{|c|}{ Standardized Coefficients } \\
\hline 1 Diff(Price,1) & $\begin{array}{c}\mathrm{B} \\
-164.050\end{array}$ & $\begin{array}{c}\text { Std. Error } \\
31.505\end{array}$ & $\begin{array}{c}\text { Beta } \\
-0.558\end{array}$ & $\begin{array}{c}\mathrm{t} \\
-5.207\end{array}$ & $\begin{array}{r}\text { Sig. } \\
0.000\end{array}$ \\
\hline
\end{tabular}

Table 3. Coefficients of demand function

The demand function of price from the table 3 is given below having checked that parameter estimate is significant.

$$
D_{k}=-164.1 P_{k}
$$

\subsection{Supply Function of Price}

The supply function of price was also formulated with production data one level lag behind that of price series data.

The two data sets were regressed and the following results obtained; 
Table 4. Coefficients of supply function

\begin{tabular}{llccccc}
\hline Model & \multicolumn{3}{c}{ Unstandardized Coefficients } & \multicolumn{3}{c}{ Standardized Coefficients } \\
\hline & B & Std. Error & Beta & $\mathrm{t}$ & Sig. \\
1 & Diff(Price,1) & 170.902 & 29.037 & 0.605 & 5.886 & 0.000 \\
\hline
\end{tabular}

a. Dependent Variable: Production_Lag $\quad$ b. Linear Regression through the Origin

Having also checked that the parameter is significant the supply function of price from the table 4 now given as;

$$
S_{k}=170.9 P_{k-1}
$$

The two models do not have any constants because they were statistically not significant.

\subsection{Cobweb Model of Fresh Tomato}

At the market clearing condition $D_{k}=S_{k}$ and hence from the equations 9 and 10 we obtain a single first-order difference equation that constitutes cobweb model as;

$$
-164.1 P_{k}=170.9 P_{k-1}
$$

Therefore

$$
P_{k}=-1.04 P_{k-1}
$$

The general solution is given by

$$
P_{k}=A^{k} P_{0} \text { where }|A|=1.04>1
$$

\subsection{Convergence conditions}

The slope of demand function of price is smaller than slope of supply function of price, that is $\mathbf{A}>\mathbf{1}$ and so the fluctuating scope would become bigger and bigger, and they never converge to the equilibrium point.

3.5 Price Stabilization: Keep Supply at Average (KSA)

If government fixes supply of fresh tomato at the average supply of $S_{k}^{A}=S_{62}^{A}=2830.1$, (see Table 4) where the average price is $\mathrm{GH} \phi 13.3897$ or $\mathrm{GH} \phi 13.40$.

Table 5. Descriptive statistics

\begin{tabular}{llllllll}
\hline Model & $\mathrm{N}$ & Minimun & Maximum & Mean & & $\begin{array}{l}\text { Std. } \\
\text { Deviation }\end{array}$ & Variance \\
\hline & Statistic & Statistic & Statistic & Statistic & Std. Error & Statistic & Statistic \\
Price & 62 & 62 & 77.31 & 13.3897 & 1.85462 & 14.60333 & 213.257 \\
Production & 62 & 643.46 & 9628.37 & 2830.0987 & 244.38452 & 1924.28561 & 3702875.092 \\
Valid & 62 & & & & & & \\
N(listwise) & & & & & & & \\
\hline
\end{tabular}

The table displays the results of statistics of the price and production data sets after analysis.

Then at market clearing condition with buffer stock

$D_{k}=S_{k}+G_{k-1}$ where $G_{k-1}=S_{k}^{A}-g\left(P_{k-1}^{e}\right)$ with $g\left(P_{k-1}^{e}\right)$ being the estimated supply at period $\mathrm{k}$. Therefore $-164.1 P_{k}=S_{k}+\left(2830.1-g\left(P_{k-1}^{e}\right)\right)$

$$
P_{k}=\frac{-1}{164.1}\left(S_{k}+\left(2830.1-g\left(P_{k-1}^{e}\right)\right)\right.
$$

This equation is used to test KSA policy price as follows using supply values from table A3 (see Appendix A)

$P_{1}=\frac{-1}{164.1}(138.429+(2830.1-0)) \quad$ where at $\mathrm{k}=1, S_{1}=138.249$ and $g\left(P_{0}^{e}\right)=0$

$P_{1}=-18.09$

The same procedure is used to obtain the other KSA values as shown below in the table 6 . The negative prices obtained in the table 6 are an indication that government always has to buy stocks from the market. 
Table 6. The results of the KSA prices in Ghe and (other relevant values)

\begin{tabular}{|c|c|c|c|c|c|c|c|c|c|}
\hline No. & Production & Prices & $\begin{array}{l}\text { Predicted } \\
\text { supply }\end{array}$ & $\begin{array}{l}\text { KSA } \\
\text { Price }\end{array}$ & No. & Production & Prices & $\begin{array}{l}\text { Predicted } \\
\text { supply }\end{array}$ & $\begin{array}{l}\text { KSA } \\
\text { Price }\end{array}$ \\
\hline 1 & 709.75 & 0.81 & 138.429 & -18.09 & 35 & 1531.52 & 7.64 & 1305.676 & -12.38 \\
\hline 2 & 1170.28 & 1.33 & 227.297 & -17.79 & 36 & 1333.43 & 6.66 & 1138.194 & -16.23 \\
\hline 3 & 773.09 & 0.88 & 150.392 & -16.78 & 37 & 1731.18 & 10.82 & 1849.138 & -21.58 \\
\hline 4 & 787.54 & 0.9 & 153.81 & -17.27 & 38 & 3605.52 & 22.54 & 3852.086 & -29.45 \\
\hline 5 & 1167.71 & 2.07 & 353.763 & -18.46 & 39 & 1632.66 & 10.21 & 1744.889 & -4.41 \\
\hline 6 & 1242.78 & 2.21 & 377.689 & -17.39 & 40 & 2527.31 & 15.8 & 2700.22 & -23.07 \\
\hline 7 & 643.46 & 1.14 & 194.826 & -16.13 & 41 & 2700.97 & 17.6 & 3007.84 & -19.12 \\
\hline 8 & 712.72 & 1.27 & 217.043 & -17.38 & 42 & 2862.68 & 18.66 & 3188.994 & -18.35 \\
\hline 9 & 7844.34 & 2.49 & 425.541 & -18.52 & 43 & 2325.64 & 15.16 & 2590.844 & -13.60 \\
\hline 10 & 9628.37 & 3.05 & 521.245 & -17.83 & 44 & 2109.71 & 13.75 & 2349.875 & -15.78 \\
\hline 11 & 8814.06 & 2.79 & 476.811 & -16.98 & 45 & 1945.62 & 18.18 & 3106.962 & -21.86 \\
\hline 12 & 4880.89 & 1.55 & 264.895 & -15.95 & 46 & 4950.15 & 46.25 & 7904.125 & -46.48 \\
\hline 13 & 4983.67 & 4.11 & 702.399 & -19.91 & 47 & 1489.26 & 13.91 & 2377.219 & 16.43 \\
\hline 14 & 5373.71 & 4.43 & 757.087 & -17.58 & 48 & 1814.97 & 16.96 & 2898.464 & -20.42 \\
\hline 15 & 3788.01 & 3.12 & 533.208 & -15.88 & 49 & 2736.9 & 21.54 & 3681.186 & -22.02 \\
\hline 16 & 1195.94 & 0.99 & 169.191 & -15.03 & 50 & 3608.29 & 28.4 & 4853.56 & -24.39 \\
\hline 17 & 1075.54 & 2.37 & 405.033 & -18.68 & 51 & 2268.27 & 17.85 & 3050.565 & -6.26 \\
\hline 18 & 4774.62 & 10.53 & 1799.577 & -25.74 & 52 & 2029.55 & 15.98 & 2730.982 & -15.30 \\
\hline 19 & 1509.5 & 3.33 & 569.097 & -9.75 & 53 & 2908.22 & 20.09 & 3433.381 & -21.53 \\
\hline 20 & 1203.01 & 2.65 & 452.885 & -16.54 & 54 & 5276.02 & 36.45 & 6229.305 & -34.28 \\
\hline 21 & 1810.26 & 3.79 & 647.711 & -18.43 & 55 & 3008.52 & 20.79 & 3553.011 & -0.94 \\
\hline 22 & 2956.33 & 6.18 & 1056.162 & -19.74 & 56 & 3280.58 & 22.67 & 3874.303 & -19.20 \\
\hline 23 & 1383.73 & 2.89 & 493.901 & -13.82 & 57 & 2869.12 & 25.22 & 4310.098 & -19.90 \\
\hline 24 & 1554.35 & 3.25 & 555.425 & -17.62 & 58 & 4101.02 & 36.05 & 6160.945 & -28.52 \\
\hline 25 & 1485.87 & 4.25 & 726.325 & -18.29 & 59 & 3615.69 & 31.79 & 5432.911 & -12.81 \\
\hline 26 & 2842.31 & 8.13 & 1389.417 & -21.29 & 60 & 3727.17 & 32.77 & 5600.393 & -18.27 \\
\hline 27 & 1616.87 & 4.63 & 791.267 & -13.60 & 61 & 4955.38 & 58.05 & 9920.745 & -43.57 \\
\hline 28 & 1896.95 & 5.43 & 927.987 & -18.08 & 62 & 6599.39 & 77.31 & 13212.28 & -37.30 \\
\hline 29 & 1982.63 & 7.52 & 1285.168 & -19.42 & 63 & 4951.96 & 58.01 & 9913.909 & 2.85 \\
\hline 30 & 2844.06 & 10.79 & 1844.011 & -20.65 & & & & & \\
\hline 31 & 1762.15 & 6.69 & 1143.321 & -12.98 & & & & & \\
\hline 32 & 1645.16 & 6.24 & 1066.416 & -16.78 & & & & & \\
\hline 33 & 2466.77 & 12.31 & 2103.779 & -23.57 & & & & & \\
\hline
\end{tabular}

The table contains values of the KSA, the production and price (actual) data sets as entered in the SPSS worksheet before the differencing and then the predicted values of supply used to obtain the KSA values.

3.6 Price Stability Check

It is clear that buffer system is more stable than non-buffer system (see figs. 1 and 2 below). The stability is also confirmed by the (table 6 below).

However, over a long term buffer system will not work properly unless the average supply or the equilibrium supply is reviewed. 


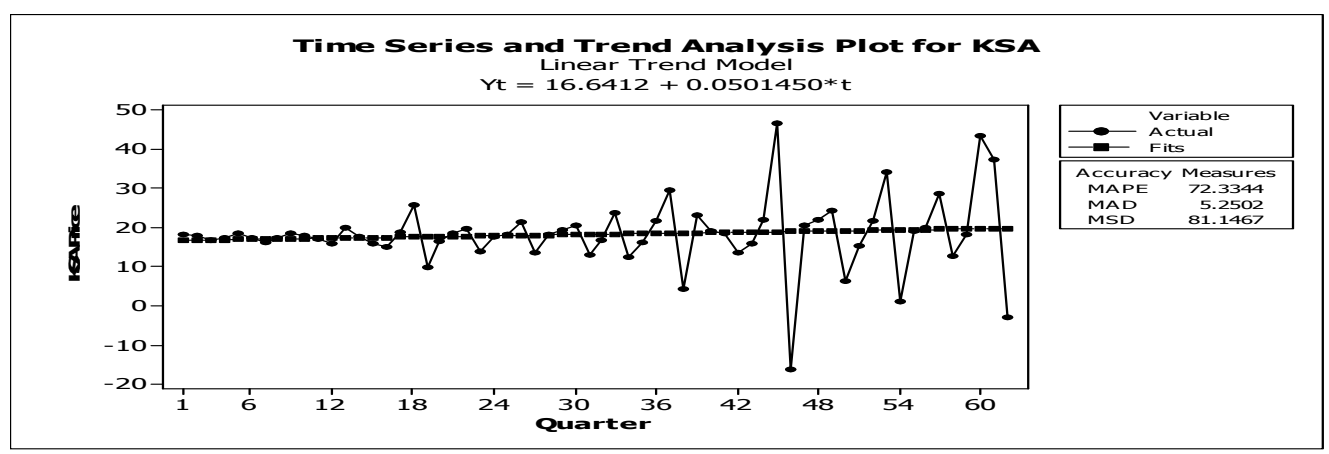

Figure 1. Price behavior policy of KSA rule

That is the graphical display of time series plot of KSA price policy values obtained in table 6 .

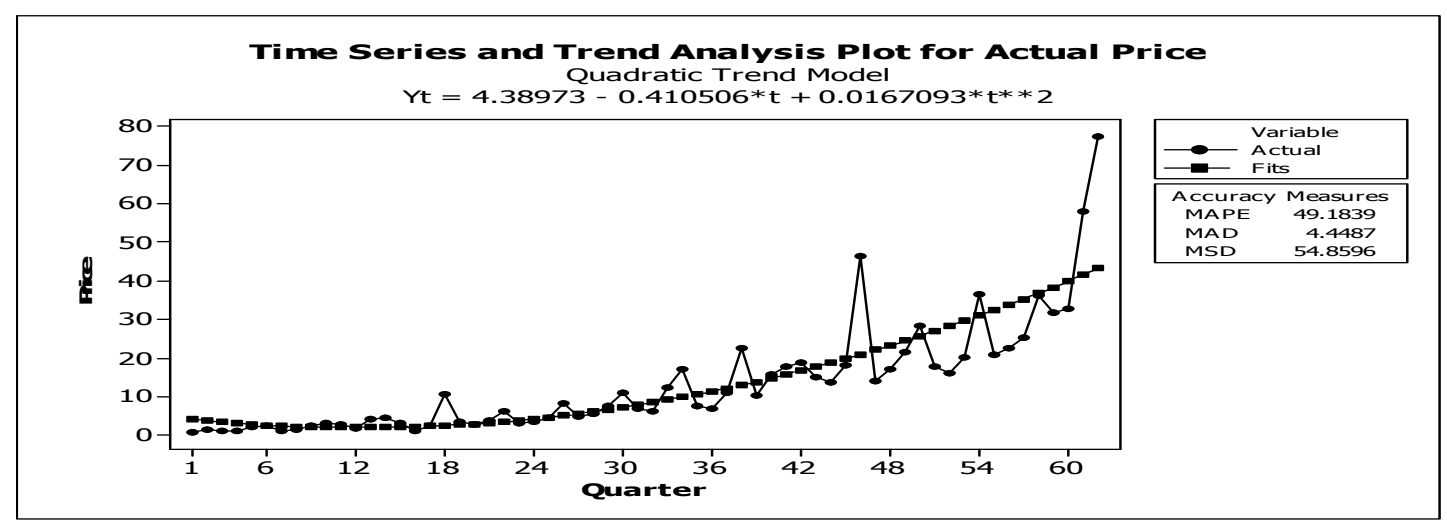

Figure 2. Trend analysis of KSA price series

That is the graphical display of time series plot of actual price policy values contained in table 6 .

Table 7. Augmented Dickey-Fuller unit root test on KSA entire price system

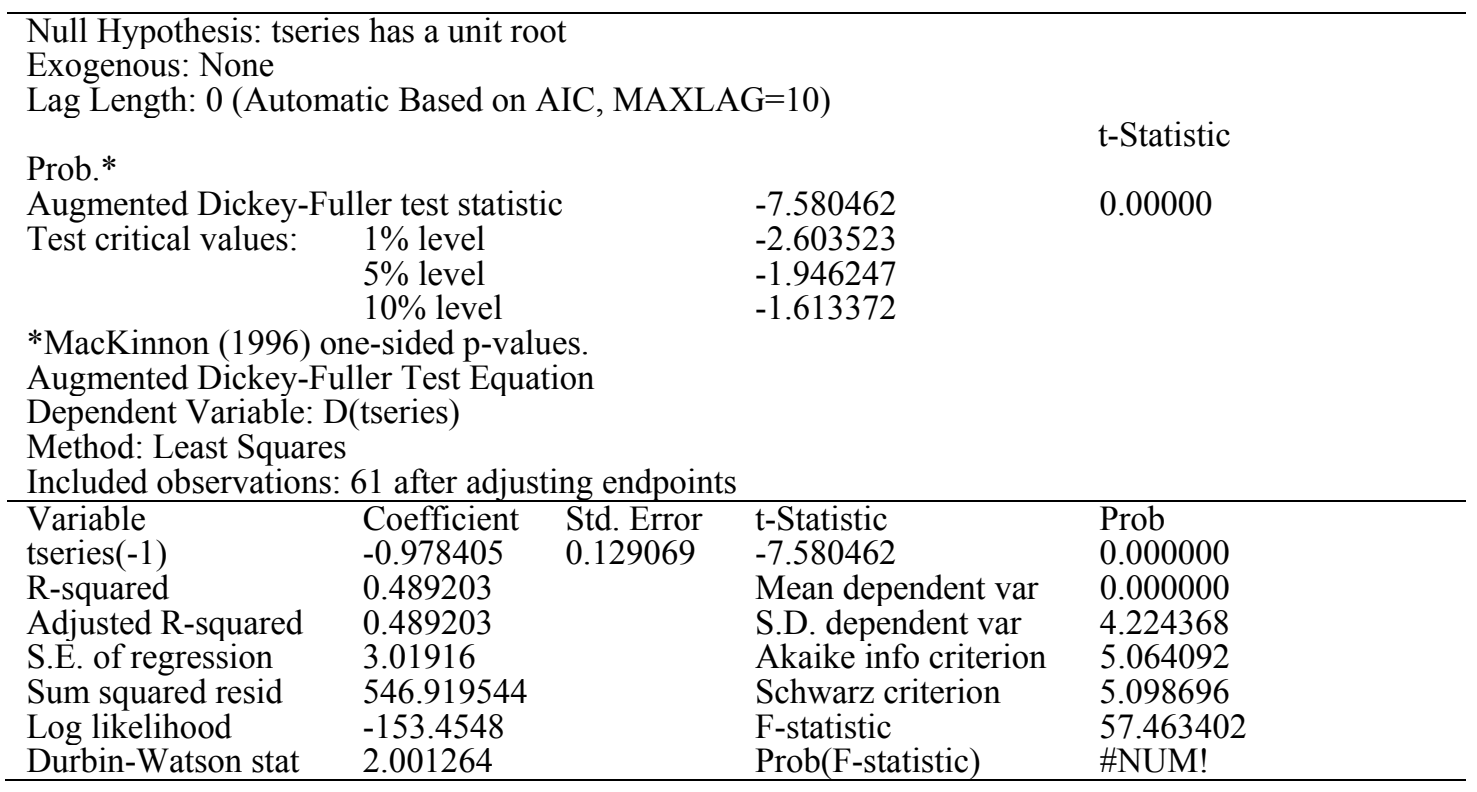


Augmented Dickey-Fuller Unit Root Test was done on the entire KSA Price System. The table 7 displays the results of the test: statistic value -7.580462 less than critical vales $-2.603523,-1.946247,-1.613372$ all at $1 \%, 5 \%$, and $10 \%$ respectively. This indicates that the series are stationary and also confirm that buffer system is more stable than non-buffer.

Table 8. Descriptive statistics: KSA (first 16 quarters), actual price and entire KSA price

\begin{tabular}{llllllll}
\hline Model & $\mathrm{N}$ & Minimun & Maximum & Mean & & \multicolumn{2}{l}{$\begin{array}{l}\text { Std. } \\
\text { Deviation }\end{array}$} \\
\hline & & & & & & Variance \\
KSA (16 quarter) & 16 & 15.03 & 19.91 & 17.3108 & 0.30008 & 1.20032 & 1.440786 \\
Price (actual) & 62 & 0.81 & 77.31 & 13.3897 & 1.85462 & 14.60333 & 213.257 \\
KSA (entire) & 62 & -16.43 & 46.48 & 18.2206 & 1.15923 & 9.12782 & 83.3171 \\
Valid N (listwise) & 16 & & & & & & \\
\hline
\end{tabular}

The table displays the results of statistics of the KSA price (at 16 quarters), actual price and entire KSA price data sets after analysis to compute the standard deviation and their means.

\section{Conclusion}

The analysis detects that the slope of demand function of price is smaller than slope of supply function of price which means that demand for fresh tomatoes is elastic to the price of the commodity. In this condition is possible for producers to make expectations error. The model performed on the assumptions that fresh tomatoes have no equal substitutes, and that there is no foreign competition and also no exogenous shocks needed to generate price fluctuations.

Keep supply average (KSA) buffer scheme was used to achieve price and quantity stability in the short run. In this buffer stock system the government fixes with the average supply and price stability guaranteed at GHф17.31, very close to actual price mean of Ghф 13.40 in the first 16 quarters. The standard deviation of KSA price data also dropped to 1.2 from 9.13 during price stabilization compared to 14.60 of the actual price data.

In the long run KSA price went up to Ghф 18.22, an increase of Ghф 0.91 and it is clear that over a long term, buffer system will not work properly unless the average supply is reviewed (see Table 7). Therefore regular adjustment of the average supply is required especially after $16^{\text {th }}$ quarter (shown in fig. 1) in order for the system to be stable and work efficiently.

The KSA trend equation $\mathrm{Yt}=16.6412+0.0501450 * \mathrm{t}$, show slow upward movement which indicates that with the implementation of the buffer scheme, the average quarterly price of fresh tomatoes increases by only 0.05 compared to the quadratic trend of the actual price (figure 2).

It is recommended that linear cobweb model could be used for the assessment of impact of policy decisions such as price stabilization programs.

From the point of view of food security objectives, buffer stocks model (equation 12) provides price stabilization and benefits producers and consumers alike, and increases efficiency. Stakeholders could process the surplus fresh tomatoes and use this model to check the price if they decide to revamp the collapsed tomato processing industry.

\section{Acknowledgements}

We are grateful to the Almighty God for he is our source of wisdom, knowledge and good health.

Finally, we are grateful to our families, and then Mr. Nortey, Mr. Fofie and Mr. Akiomi all of Ministry of Food and Agriculture for their assistance.

\section{References}

Amikuzuno, J. (2009). Spatial Price Transmission and Market Integration between Fresh Tomato Markets in Ghana: Any Benefits from Trade Liberalisation? Department of Agricultural Economics and Extension, University for Development Studies, Tamale, Ghana.

Athanasiou, G., Iasson, K., \& Kotsiosa, S. (2010). Price stabilization using buffer stocks. Retrieved August 10, 2010, from http://www.sciencedirect.com

Athanasioua, G., Karafyllis, I., \& Kotsiosa, S. (2008). Price stabilization using buffer stocks. Journal of Economic Dynamics \& Control, 32, 1212-1235. http://dx.doi.org/10.1016/j.jedc.2007.05.004 
Bahagia, N. S. (2006). Inventory System. Penerbit ITB, Bandung, Published in Indonesia.

Cafiero, C., \& Wright, B. D. (2006). Is the storage model a 'closed' empirical issue? The empirical ability of the storage model to explain price dynamics. In Sarris \& Hallam (Eds.), Agricultural commodity markets and trade: new approaches to analyzing market structure and instability (pp. 89-114). Retrieved from http://www.cabdirect.org/abstracts/20063047862.html

Deaton, A., \& Laroque, G. (1996). Competitive Storage and Commodity Price Dynamics. J. of Pol. Econ., 104, 896-923. http://dx.doi.org/10.1086/262046

Deaton, A., \& Laroque, G. (1992). On the Behavior of Commodity Prices. Review of Econ. Studies, 59, 1-23. http://dx.doi.org/10.2307/2297923

Edwards, R., \& Hallwood, C. P. (1980). The Determination of Optimum Buffer Stock Intervention Rules. The Quarterly Journal of Economics, 94(1), 151-166. http://dx.doi.org/10.2307/1884609

Ezekiel, M. (1938). The Cobweb Theorem. Quart. J. Econ., 52, 255-280. http://dx.doi.org/10.2307/1881734

FAO. (2006). Ghana: Rice, Poultry and Tomato Paste. Briefs on Import Surges, 5, 4.

Fulford, G., Forrester, P., \& Arthur, J. (1997). Modelling with differential and difference equations. Cambridge university press, $138-140$.

Gomez, I. A., Love, H. A., \& Burton, D. M. (1999). Alternative Price expectations Regimes in Timber markets. Journal of Forest economics, 5(2).

Hommes, C. H. (1994). Dynamics of the cobweb model with adaptive expectations and nonlinear supply and demand. J. Econ. Behav. Org., 24, 315-335. http://dx.doi.org/10.1016/0167-2681(94)90039-6

Honkapohja, S., \& Evans, G. W. (2001). Learning and Expectations in Macroeconomics. Princeton University Press.

Kirchgässner, G., \& Wolters, J. (2007). Introduction to modern time series. Springer-Verlag Berlin Heidelberg, 11.

Kokutse, F. (2010). Tomato Queens Short-Change Farmers. Retrieved August 17, 2010, from http://ipsnews.net/africa

Matsumoto, A. (1998). Do government subsidies stabilize or destabilize agricultural markets? Contemporary Economic Policy. Retrieved July 27, 2010 from http:// findarticles.com/p/search

Morrow, D. T. (1980). The economics of the international stockholding of wheat. International Food Policy Research Institute. Retrieved April 23, 2010 from http://books.google.com/books?id=czEts2pPxq4C.

Muth, J. F. (1961). Rational Expectations and the Theory of Price Movements. Econometrica, 29(3), 315-335. http://dx.doi.org/10.2307/1909635

Nerlove, M. (1958). Adaptive Expectations and Cobweb Phenomena. Quarterly J. of Econ., 72, 227-240. http://dx.doi.org/10.2307/1880597

Ruize, W. (2010). Test on the Economics Cobweb Model by Using Eviews Programming. Retrieved November 8 , 2010 from http://www.ieeexplore.ieee.org

Sargent, T. J. (1987). Rational expectations. The New Palgrave: A Dictionary of Economics, 4, 76-79.

Savin, N. E. (1987). Rational expectations: econometric implications. The New Palgrave: A Dictionary of Economics, 4, 79-85. 